\title{
Carotid blowout syndrome after intensity-modulated radiation therapy: A case report
}

\author{
Yoğunluk ayarlı radyoterapi sonrasında gelişen carotid blowout sendromu: Olgu sunumu
}

Bilgehan SAHIN, Banu ATALAR, Abdullah YAKUPOGLU, Enis OZYAR

\begin{abstract}
Carotid blowout syndrome (CBS) is a rarely seen complication of head-neck surgery and radiation therapy. It may present by massive ear bleeding or epistaxis with high morbidity and mortality rates. Success rate of endovascular therapy or emergency surgery is unfortunately low because of massive bleeding and weakened vessel architecture. Here, we present a 45-year-old male with nasopharyngeal carcinoma and treated with intensity-modulated radiation therapy (IMRT) and concurrent chemotherapy. The patient was diagnosed with stage III (T3N2M0) carcinoma of the nasopharynx. Eight months after radiotherapy, he was admitted to hospital with the complaint of epistaxis. Right internal carotid angiography revealed a $4 \mathrm{~mm}$ pseudoaneurysm at the superioranterior wall of the petrous and his bleeding was controlled by stenting in the same session. In this report we aimed to draw attention to this rare clinical situation that might enhance the chance of early diagnosis enabling less morbid treatment opportunities.
\end{abstract}

Keywords: IMRT, Carotid blowout syndrome, CBS, Pseudoaneurysm

Bilgehan Sahin $(\varangle)$

Radiation Oncology Clinic, Maslak Acibadem Hospital, Maslak, Istanbul, Turkey

e-mail:bsahin@yahoo.com

Banu Atalar, Enis Ozyar

Department of Radiation Oncology, School of Medicine, Acibadem University, Altunizade, Istanbul, Turkey

Abdullah Yakupoglu

Interventional Radiology Clinic, Sisli Florence Nightingale Hospital, Sisli, Istanbul, Turkey

Submitted / Gönderilme: 11.02.2017

Accepted/Kabul: 21.03 .2017
Öz

Carotid blowout sendromu (CBS) veya pseudoaneurysm, baş-boyun cerrahisi ve radyoterapi sonrası nadir görülen bir komplikasyondur. Yüksek morbidite ve mortalite oranları ile masif kulak kanaması veya epistaksis şeklinde görülür. Zayıflamış damar yapısı ve masif kanama sebebiyle acil cerrahi ya da endovasküler tedavilerin başarı şansı oldukça düşüktür. Bu yazıda, nazofarenks kanseri tanısı olan ve eş zamanlı kemoterapi ile beraber yoğunluk ayarlı radyoterapi (YART) $\mathrm{C}$ alan 3. evre (T3N2M0), 45 yaşında erkek hasta sunulmuştur. Radyoterapi sonrasi 8. ayda epistaksis ile hastaneye başvuran hastanın sağ internal carotis arter anjiografisinde petros segmentin antero-superior duvarında $4 \mathrm{~mm}$ pseudoanevrizma saptanıp aynı seansta stentle kanama kontrolu yapılmıştır. Bu yazıda, erken tanı konulabilmesi ve dolayısıyla daha az morbid tedavi seçeneklerinin sunulabilmesi için nadir görülen bu klinik duruma dikkat çekilmesi amaçlanmıştır.

Anahtar kelimeler: YART, Carotid blowout sendromu, CBS, Pseudoanevrizma

\section{Introduction}

Pseudoaneurysm, rupture of the carotid artery, or carotid blowout syndrome (CBS) is a rare complication of head and neck surgery and radiotherapy. Mostly after reirradiation, a cascade of reactions occurs in the endothelial cells which causes disruption of the arterial wall leading to pseudoaneurysms. Herein, we report a nasopharyngeal cancer (NPC) patient who was diagnosed as CBS, 8 months after chemoradiotherapy and treated with stent implantation [1].

\section{Case Report}

A 45-year-old man referred to our department with the diagnosis of undifferentiated NPC in April 2013. His 
magnetic resonance imaging (MRI) scan revealed a nasopharyngeal mass lesion which invaded the base of the skull bones and posterior wall of the right maxillary sinus with bilateral pathologic level IIB lymph nodes. His positron emission tomography - computed tomography (PET-CT) scan revealed a nasopharyngeal primary tumor with bilateral level II metastatic lymph nodes and no distant metastasis. Thus, he was staged as T3N2M0 - Stage III. His pretreatment plasma Epstein-Barr virus (EBV) DNA level was $18.370 \mathrm{cp} / \mathrm{ml}$ before the treatment.

Between, 3 September 2013 and 22 October 2013, the patient was treated with concomitant chemoradiotherapy using 3-weekly cisplatinum. Radiotherapy was applied by using volumetric modulated arc treatment with $6 \mathrm{MV}$ photons. Simultaneous integrated boost technique was used to give a total dose of $6990 \mathrm{cGy}$ to the nasopharyngeal primary, retropharyngeal lymphadenopathy and all gross nodal disease, $6000 \mathrm{cGy}$ to the entire nasopharynx (includes retropharyngeal lymph nodal regions, clivus, skull base, pterygoid fossae, parapharyngeal space, inferior sphenoid sinus and posterior third of the nasal cavity and maxillary sinuses), bilateral upper neck node regions and 5600 cGy to the supraclavicular lymph nodes in 33 fractions. Grade 2 mucositis, dermatitis, esophagitis, local alopecia, and neutropenia developed during treatment. One month after treatment his plasma EBV DNA level was found to be negative. His follow-up PET-CT revealed partial response at nasopharynx and complete response at nodal disease, however, skeletal metastasis developed at thoracal vertebras and pelvic bones 3 months after concomitant chemoradiotherapy. His plasma EBV DNA level at recurrence was $1.352 \mathrm{cp} / \mathrm{ml}$. He received one cycle of combined Taxotere - Cisplatin $-5 \mathrm{Fu}$ (TPF) (Taxotere - Cisplatin - 5Fu) chemotherapy but he refused to get chemotherapy thereafter.

Eight months after the termination of radiotherapy he admitted to our hospital with the complaint of epistaxis. It was learnt that minimal epistaxis had been present for a few week before presentation. Otolaryngological examination revealed oozing type of epistaxis originating from nasopharyngeal region. Initially, simple transnasal tamponade was inserted and red blood cell transfusions were given. Under general anesthesia, bilateral externalinternal carotid digital substraction angiography (DSA) was performed. Right internal carotid angiographies revealed a $4 \mathrm{~mm}$ pseudoaneurysm at the superior-anterior wall of the petrous segment (Figure 1). Because of poor crossflow through the circle of Willis, parent artery protection

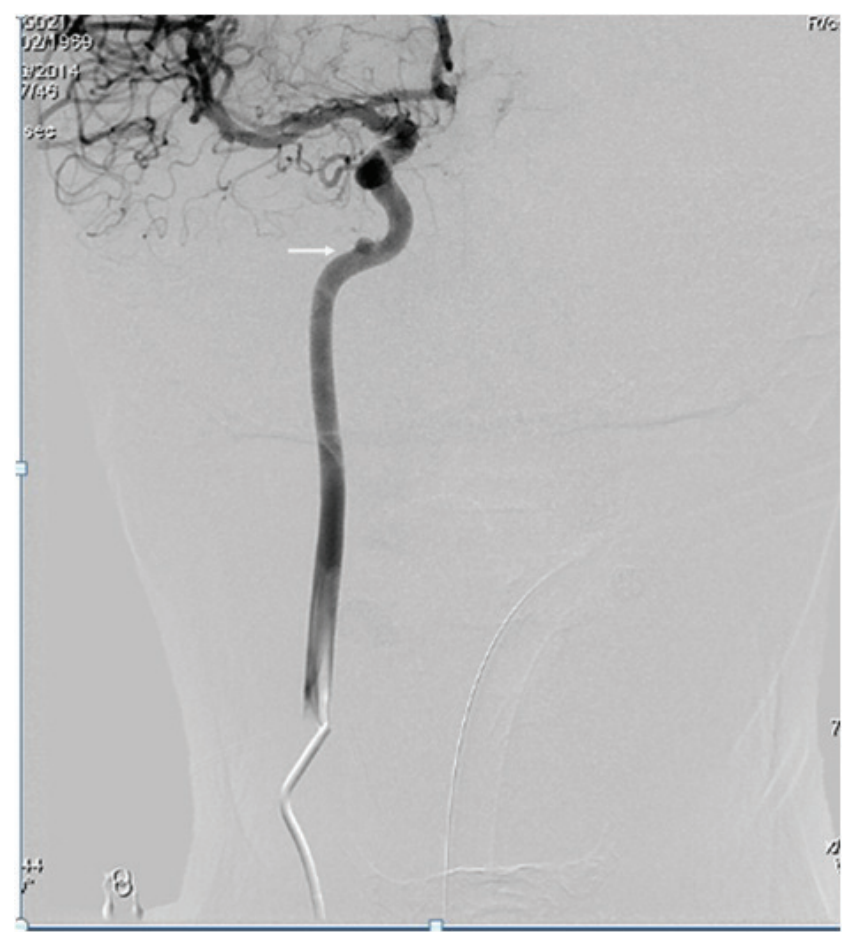

Figure 1: Right internal carotid artery DSA; white arrows are showing pseudoaneurysm in the petrous segment.

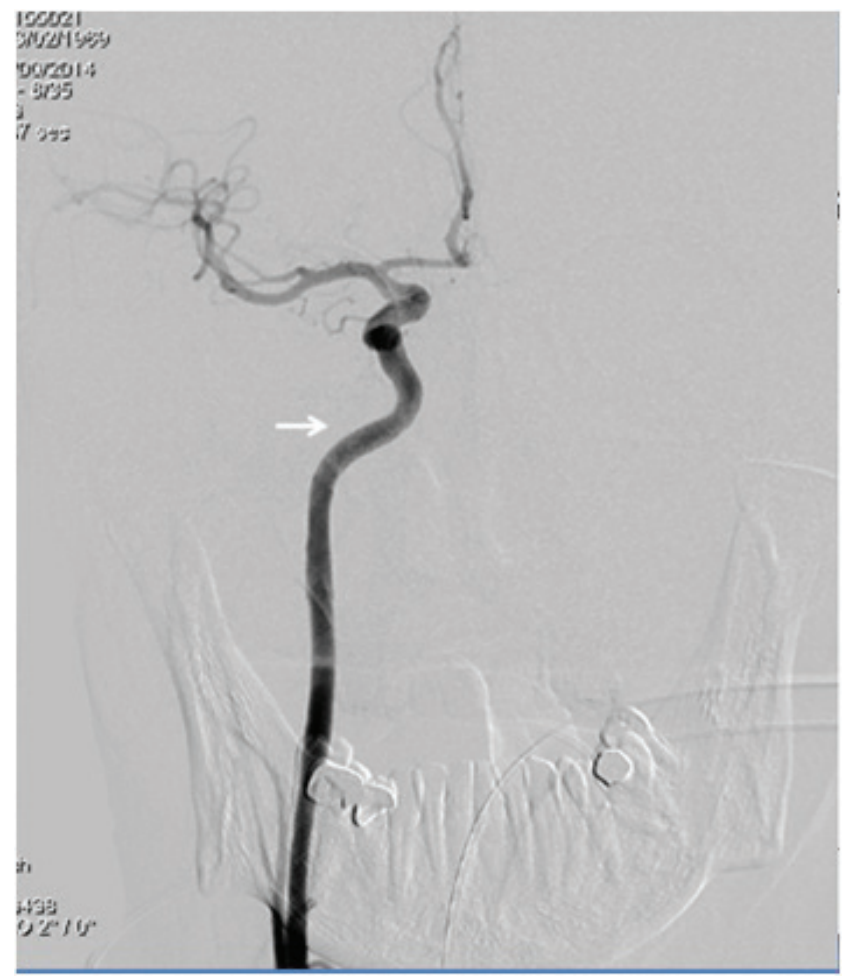

Figure 2: Right internal carotid artery DSA after stent-graft implantation; white arrows showing patency of the parent artery and lack of filling of the pseudoaneurysm with good reconstruction. 
was needed. The patient received a loading dose of clopidogrel through the nasogastric tube in the operating room and implantation of a drug eluded stent (Be Graft $5 \times 22 \mathrm{~mm}$ ) was performed in the same session. Control DSA demonstrated closure of the pseudoaneurysm and bleeding was controlled successfully (Figure 2). Following removal of nasal bandages intraoperatively, repeat DSA showed absence of filling of pseudoaneurysm and no nasal bleeding was observed. After stent implantation no neurological complication was observed, antithrombotic therapy was continued. The patient is still alive with disease.

\section{Discussion}

Pseudoaneurysm rupture of the carotid artery, or CBS is a rare but dreadful complication of head and neck surgery and/or radiotherapy. In a recent review by Powitzky et al., clinicopathologic features of CBS in patients with head and neck cancer was evaluated. They performed a retrospective review of all studies documenting $132 \mathrm{CBS}$ cases with head and neck cancer from 21 studies. They found that patients with CBS typically have a history of radiotherapy (89\%), nodal metastasis $(69 \%)$, and neck dissection (63\%). They indicated that morbidity and mortality rates of patients with CBS are significant; only $23 \%$ have survived. Almost $50 \%$ of the CBS patients presented with sentinel bleeding, but other half of patients developed a life-threatening hemorrhage requiring emergent intervention [2].

Acute carotid rupture occurs when a compromised arterial wall cannot maintain its integrity against relatively high blood pressure. Disruption of the integrity of the arterial wall may be caused by direct involvement of malignancy, by infection of fistula or an abscess, by loss of overlying soft tissue, or by desiccation effects of skin involvement, or by apoptotic and inflammatory reaction of radiotherapy causing vascular endothelial damage, or by combination of these factors [3]. Some of the predisposing factors that can lead to CBS include radiation, surgery, trauma, diabetes mellitus, poor nutrition, prolonged corticosteroid use, and uncontrolled hypertension [4]. As our presented case, was treated only with radiotherapy and chemotherapy, we believe that formation of this pseudoaneurysm was due to the treatment as there were no any other aforementioned predisposing factors which may lead to this complication.

Carotid blowout syndrome was a very rare event during the 3-D conformal radiotherapy era. Bleeding was also reported rarely after inensity-modulated radiotherapy
(IMRT) treatment in the literature. Simultaneous integrated boost (SIB) technique is commonly used in patients treated with head and neck IMRT. This technique allows for improved dose differential by administering different fractional doses to different targets in the same treatment. SIB is a new accelerated fractionation schedule for the treatment of head-and-neck cancer with IMRT. Thus, besides physical dose escalation in the tumor, a biologic effect of accelerated fractionation can occur within tumor also. Lee et al., reported bleeding rate of $1.5 \%$ and death rate of $1.5 \%$ in median follow up of 2.6 years in patients treated with IMRT. Only one patient died of uncontrolled epistaxis approximately 6 months after completion of IMRT; however, the cause of death was not defined [5]. Kwong et al., reported bleeding rate of $4 \%$ and no death was reported in median follow up of 2.1 years. Two patients developed carotid pseudoaneurysm - one received both IMRT and subsequent stereotactic radiosurgery for persistent disease in nasopharynx and the other patient received IMRT and chemotherapy. Both patients presented with sudden onset of torrential epistaxis at about 7 months after completion of IMRT. Emergency surgical intervention successfully controlled the bleeding pseudoaneurysm in both cases [6]. Lin et al., reported bleeding rate of $0.3 \%$ and death rate of $0.6 \%$. [7]. All three series who reported CBS treated their patients using SIB technique and their prescription dose to the primary tumor ranged between 2.12-2.25 Gy, 2.17 Gy and 2.2-2.25 Gy and total dose ranged between 65-70 Gy, 76 Gy and 66-70 Gy, respectively. It is well known that SIB technique may cause maximum doses in the target which exceeds $>110 \%$ to $120 \%$ of the prescribed dose. According to Radiation Therapy Oncology Group (RTOG) 0225 nasopharyngeal cancer protocol, if greater than $5 \%$ of the PTV70 receives greater than $115 \%$ of prescribed dose, this situation is scored as major variation and these patients were considered noncompliant to the study [5].

In our patient, we tried to identify the maximum dose received for the superior-anterior wall of petrous segment of the right internal carotid artery (ICA). We made a fusion of treatment planning $\mathrm{CT}$ and post stent $\mathrm{CT}$ to document this high dose area (Figure 3). This dose ranges between 7350 cGy to 7969 cGy $(105 \%$ to $113 \%$ of the prescribed dose). Mc Donald et al., reported that increasing the daily dose with hypofractionation would cause 3-fold increase incidence of CBS. In this case, high dose concentration with SIB technique could be the most enhancing causative factor for the development of the pseudoaneurysm [4]. 


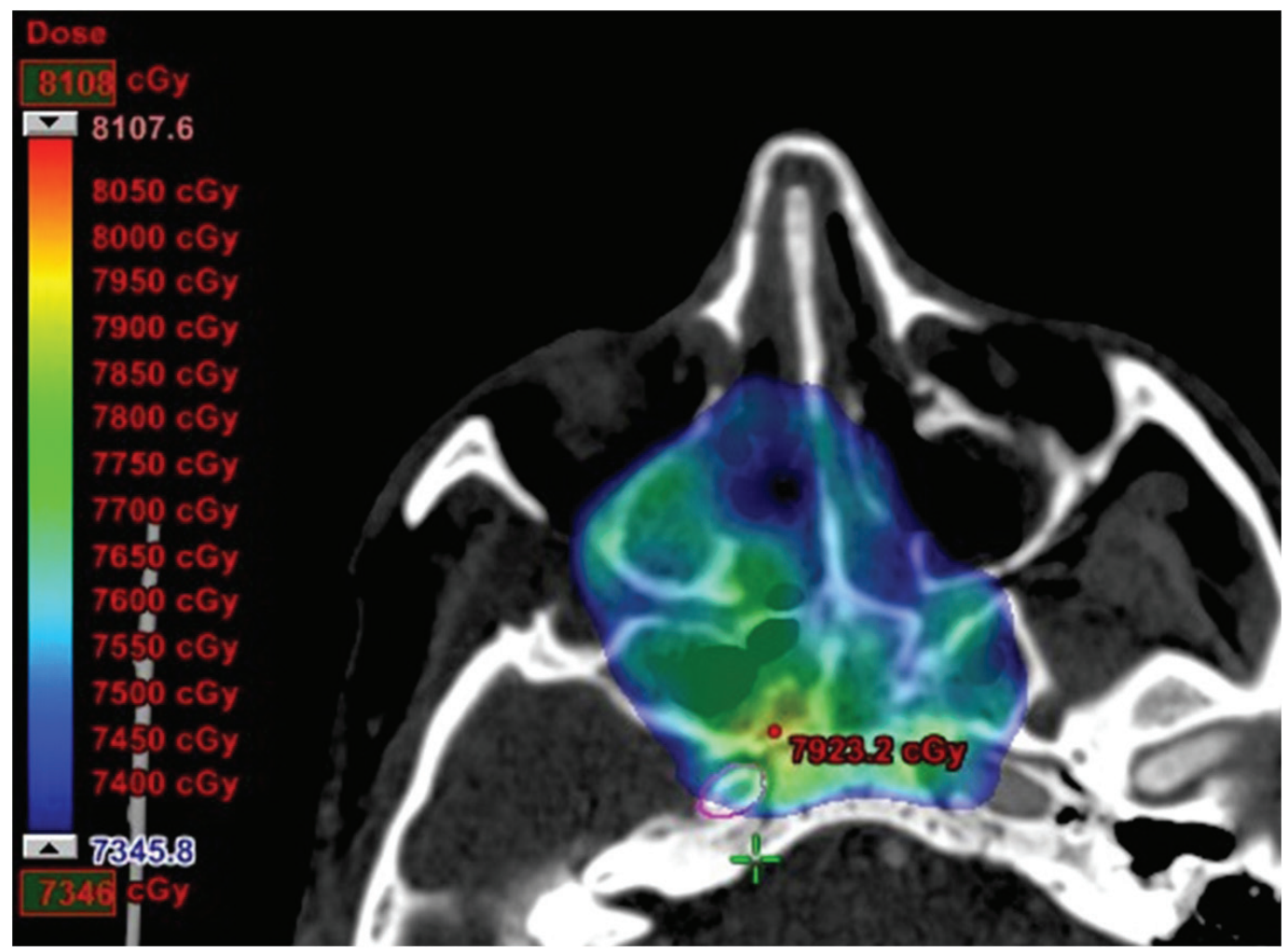

Figure 3: Axial view ; the relationship of the pseudoaneurysm with high dose area (Purple Line: Stent ; Colour wash illustration shows 105 $\%$ of the prescribed dose )

Although, IMRT and stereotactic body radiation therapy (SBRT) techniques are designed to minimize the dose of the radiation for the healthy tissue surrounding the tumor, we currently have little feedback on early and late toxicity of these techniques. This is mainly due to limited data including long term follow-up and to less precise knowledge of the radiobiology of high doses of radiation. The conventionally used model for predicting tumor response and normal tissue toxicity is the cell survival lineer quadratic model. This model is essentially based on repair and death mechanism related to radiation induced DNA damage [8]. However, other molecular mechanisms may be involved in the normal tissues other than cancer cell cultures. Among these pathways, the microvascular endothelial compartment has been shown to play a major role in radiation toxicity. Radiation levels above 10 Gy cause endothelial cells to enter apoptotic cell death ending with damage to the microvascular network. After apoptosis surviving cells secrete excessively pro-inflammatory cytokines causing activation of the coagulation system and increased vascular permeability. Late effects include microvascular collapse and thickening of the basement membrane and distruption of the normal architecture of the vessel wall. Dose escalation by using IMRT and SBRT techniques may lead to a different mechanism. Acid sphingomyelinase (ASMase)/ ceramide pathway requires more than conventional doses to be activated. It was shown that this pathway was not triggered in tissues exposed to conventional fractionated radiotherapy. These alternative pathways would be causative factors which lead to unexpected clinical results of the high doses by using IMRT and SBRT techniques [3].

While CBS incidence is very low after postoperative or definitive radiotherapy, this risk significantly increases in patients treated with re-irradiation or subsequent stereotactic radiosurgery boost for persistent disease after definitive radiotherapy. Local recurrence after definitive radiotherapy remains a major issue and nasopharynx is the most suitable site for re-irradiation. However, anatomic location and need for a high dose irradiation make this treatment extremely challenging. Conventional radiotherapy produced less optimal outcome and was associated with high rate of late toxicity. IMRT is a better strategy with better dose distribution. One year local control ranged between $44 \%$ $100 \%$ depending on T stage in the literature. However, Grade III toxicity rate ranged between $19 \%$ to $36 \%$. $[9,10,11]$ Tian 
et al., reported their experience in patients with locally recurrent nasopharyngeal carcinoma treated with IMRT in a phase 2 randomized controlled trial. They reported that hypofractionation increasing dose per fraction from 200 cGy to 222 cGy causes significantly higher incidences of mucosal necrosis and hemorrhage (from $28.8 \%$ to $50.8 \%$ ) and lower overall survival (44.2\% vs 30.3\%) [12]. Similarly Yamazaki et al., informed increased risk for CBS by enhanced dose concentration and high BED values [13]. In our case, time between radiotherapy and the CBS is 8 months. In the literature, this duration varies from during radiotherapy to 17 years, but CBS was mostly seen in a year after radiotherapy. This variation suggests the possibility of having different pathways of underlying pathologic processes [4].

Stereotactic radiosurgery with single high dose radiation or stereotactic radiotherapy using high dose per fraction are other strategies for re-irradiation. Cranial neuropathy, trismus, epistaxis, temporal lobe necrosis, osteoradionecrosis and fatal CBS are among the late complications. Recently, Cengiz et al., reported 46 recurrent, unresectable, and previously irradiated head-and-neck cancer patients treated using robotic hypofractionated radiotherapy. Their median tumor dose was $30 \mathrm{~Gy}$ in a median of five fractions. Oneyear progression-free survival and overall survival were $41 \%$ and $46 \%$, respectively. They reported Grade II or greater long-term complications rate of $13.3 \%$. However, they also reported that $8(17.3 \%)$ patients developed CBS on follow-up, and $7(15.2 \%)$ patients died because of bleeding of the carotid arteries. They discovered that CBS occurred only in patients with tumor surrounding carotid arteries and carotid arteries receiving all prescribed dose. Authors, changed their treatment protocol due to the high rate of CBS, treated following 32 patients every other day in a prospective protocol. Three out of 32 patients developed CBS with the new treatment strategy with relatively short follow up time. They also mentioned that CBS did not occur in any of the patients with a maximum carotid artery radiation dose of $<34$ Gy [15].

Carotid blowout syndrome was historically observed among patients who had recurrent disease after re-irradiation or salvage surgery. However, with more aggressive primary treatment, we may observe more of this complication in the future. Excessive doses in the planning target volume (PTV) should be avoided in the absence of gross tumor volume. Also, clinicians need to be aware of this potential complication in patients who present with severe epistaxis after treatment. Patients who are at high risk for CBS should be followed by MRI angiography beside routine MRI. Emergency resuscitation and interventions should be applied in these patients.

As a consequence; CBS is a rarely seen complication of head and neck surgery and radiation therapy. It may present by massive ear bleeding or epistaxis with high morbidity and mortality rates. Success rate of endovascular therapy or emergency surgery is unfortunately low because of massive bleeding and weakened vessel architecture. In this casereport we aimed to draw attention to clinical changes in patients after radiation therapy that may alert clinicians and elective angiography after local therapies of head and neck surgery might enhance the chance of early diagnosis that enables less morbid treatment opportunities.

\section{References}

1. Chaloupka JC, Putman CM, Citardi MJ, et al. Endovascular therapy for the carotid blowout syndrome in head and neck surgical patients: Diagnostic and managerial considerations. AJNR Am J Neuroradiol 1996;17:843-52.

2. Powitzky R, Vasan N, Krempl G, Medina J. Carotid blowout in patients with head and neck cancer. Ann Otol Rhinol Laryngol 2010; 119: 476-84. doi: 10.1177/000348941011900709

3. Corre I, Niaudet C, Paris F. Plasma membrane signaling induced by ionizing radiation. Mutat Res 2010; 704, 61-7. doi: 10.1016/j.mrrev.2010.01.014

4. McDonald MW, Moore MG, Johnstone PA. Risk of carotid blowout after reirradiation of the head and neck: a systematic review. Int J Radiat Oncol Biol Phys 2012;82:1083-9.doi: 10.1016/j.ijrobp.2010.08.029

5. Lee N, Harris J, Garden AS, et al. Intensity-modulated radiation therapy with or without chemotherapy for nasopharyngeal carcinoma: radiation therapy oncology group phase II trial 0225. J Clin Oncol 2009;27:3684-90. doi: 10.1200/JCO.2008.19.9109

6. Kwong DL, Sham JS, Leung LH, et al. Preliminary results of radiation dose escalation for locally advanced nasopharyngeal carcinoma. Int J Radiat Oncol Biol Phys 2006;64:374-81. doi: http://dx.doi.org/10.1016/j.ijrobp.2005.07.968

7. Lin YW, Chen CC, Lin LC, Lee SP. The impact of reduced-volume, intensity-modulated radiation therapy on disease control in nasopharyngeal carcinoma. PLoS ONE. 2015;10:e0125283. doi: https://doi.org/10.1371/journal. pone. 0125283

8. Mohan R, Wu Q, Manning M, Schmidt-Ullrich R. Radiobiological considerations in the design of fractionation strategies for intensity-modulated radiation therapy of head and neck cancers. Int J Radiat Oncol Biol Phys 2000;46:61930 .

9. Qiu S, Lin S, Tham IW, et al. Intensity-modulated radiation therapy in the salvage of locally recurrent nasopharyngeal 
carcinoma. Int J Radiat Oncol Biol Phys 2012;83:676-83. doi: 10.1016/j.ijrobp.2011.07.006.

10. Chua DT, Sham JS, Kwong PW, et al. Linear acceleratorbased stereotactic radiosurgery for limited, locally persistent, and recurrent nasopharyngeal carcinoma: efficacy and complications. Int J Radiat Oncol Biol Phys 2003;56:177-83.

11. Lu TX, Mai WY, Teh BS, et al. Initial experience using intensitymodulated radiotherapy for recurrent nasopharyngeal carcinoma. Int J Radiat Oncol Biol Phys 2004;58:682-7. doi: 10.1016/S0360-3016(03)01508-6

12. Tian YM, Zhao C, Guo Y, et al. Effect of total dose and fraction size on survival of patients with locally recurrent nasopharyngeal carcinoma treated with intensity-modulated radiotherapy: A phase 2, single-center, randomized controlled trial. Cancer 2014; 120:3502-9. doi: 10.1002/cncr.28934,

13. Yamazaki H, Ogita M, Kodani N, et al. Frequency, outcome and prognostic factors of carotid blowout syndrome after hypofractionated re-irradiation of head and neck cancer using CyberKnife: a multi-institutional study. Radiother Oncol 2013;107:305-9.

14. Yazici G, Sanlı T Y, Cengiz M, et al. A simple strategy to decrease fatal carotid blowout syndrome after stereotactic body reirradiaton for recurrent head and neck cancers. Radiat Oncol 2013; 8: 242. doi: 10.1186/1748-717X-8-242

15. Cengiz M, Ozyigit G, Yazici G, et al. Salvage reirradiaton with stereotactic body radiotherapy for locally recurrent headand-neck tumors. Int J Radiat Oncol Biol Phys 2011;81:1049. doi: 10.1016/j.ijrobp.2010.04.027 